\title{
Better the devil you know? Nonconscious processing of identity and affect of famous faces
}

\author{
ANNA STONE and TIM VALENTINE \\ Goldsmiths College, University of London, London, England
}

\begin{abstract}
The nonconscious recognition of facial identity was investigated in two experiments featuring brief (17-msec) masked stimulus presentation to prevent conscious recognition. Faces were presented in simultaneous pairs of one famous face and one unfamiliar face, and participants attempted to select the famous face. Subsequently, participants rated the famous persons as "good" or "evil" (Experiment 1) or liked or disliked (Experiment 2). In Experiments 1 and 2, responses were less accurate to faces of persons rated evil/disliked than to faces of persons rated good/liked, and faces of persons rated evil/disliked were selected significantly below chance. Experiment 2 showed the effect in a within-items analysis: A famous face was selected less often by participants who disliked the person than by participants who liked the person, and the former were selected below chance accuracy. The within-items analysis rules out possible confounding factors based on variations in physical characteristics of the stimulus faces and confirms that the effects are due to participants' attitudes toward the famous persons. The results suggest that facial identity is recognized preconsciously, and that responses may be based on affect rather than familiarity.
\end{abstract}

There is considerable evidence that facial expressions can be detected preconsciously and can influence psychophysiological and behavioral responses without awareness (e.g., Dimberg \& Öhman, 1996; Dimberg, Thunberg, \& Elmehed, 2000; Johnsen \& Hugdahl, 1991, 1993; Mogg \& Bradley, 1999; Murphy \& Zajonc, 1993; Niedenthal, 1990; Öhman, Esteves, \& Soares, 1995; Saban \& Hugdahl, 1999; Whalen et al., 1998; Wong, Shevrin, \& Williams, 1994; see Robinson, 1998, for a review). In all of these studies, conscious awareness was prevented by presenting masked faces for very brief exposure duration, using target-to-mask stimulus onset asynchrony (SOA) of less than $35 \mathrm{msec}$. The absence of awareness was verified by chance performance in twoalternative forced choice tasks on stimuli presented under conditions similar to the experiment tasks.

The question arises of whether facial identities, like facial expressions, can be detected without conscious awareness. While there is a strong body of evidence supporting covert face recognition in prosopagnosia (e.g., Young, 1998, offers an extensive review), there is less empirical support for the nonconscious recognition of facial identity by neurologically intact participants. Ellis, Young, and Koenken (1993) and Morrison, Bruce, and Burton (2000) claim to have demonstrated nonconscious perception of facial identity, but it is unclear from the methodology that conscious recognition was entirely ab-

Correspondence should be addressed to A. Stone, Psychology Department, Goldsmiths College, New Cross, London SE14 6NW, England (e-mail: pss01as@gold.ac.uk). sent from exposure duration in excess of $50 \mathrm{msec}$ (see Stone, Valentine, \& Davis, 2001, for a critique of their methods).

Stone et al. (2001, Experiment 1) reported that skin conductance responses to consciously unrecognized masked $17-\mathrm{msec}$ faces were higher to the faces of famous persons subsequently rated "good" than to the faces of persons rated "evil," but did not distinguish between the faces of famous and unfamiliar persons (responses tended to be higher to "good" faces than to unfamiliar faces, but tended to be lower to "evil" faces than to unfamiliar faces). Conversely, when faces were exposed for $200 \mathrm{msec}$, a duration that permits conscious recognition, there was an effect of familiarity but no effect of valence: Skin conductance responses were higher to famous faces than to unfamiliar faces with no difference between "good" and "evil" faces. Responses were above chance accuracy in a two-alternative forced choice of good or evil to masked 17-msec famous faces that were not consciously recognized (Experiment 3 ). It appears that when famous faces are perceived nonconsciously, responses are based on affective valence but not based on familiarity per se.

The model of face recognition proposed by Breen, Caine, and Coltheart (2000) offers an explanation. This model describes two parallel routes: the semantic route, concerned with familiarity detection (based on the Bruce \& Young, 1986, model of face recognition, extended and developed by Burton, Bruce, \& Johnston, 1990), and the affective route, which mediates responses on the basis of the emotional significance of a face. The results of Stone et al. (2001) suggest that when faces are presented with- 
out conscious awareness to unimpaired participants, the affective route is activated, resulting in discrimination of faces according to their affective valence, detectable by autonomic and behavioral measures. The semantic route, on the other hand, is either insufficiently activated or is overridden by the affective response, so there is no autonomic discrimination of face familiarity.

The experiments reported here investigated differential responses to faces of famous persons regarded as good/liked and evil/disliked using an alternative behavioral measure. Two faces were presented simultaneously for $17 \mathrm{msec}$, one each in left visual field (LVF) and right visual field (RVF), with each pair comprising one famous and one unfamiliar face. Participants were asked to guess in which visual field the famous face had appeared. The logic of the design is as follows. If participants were able to recognize faces consciously, then the task of selecting the famous face would be easy, so overall performance at the level of chance demonstrates the absence of conscious recognition. On the basis of previous unpublished experiments and Stone et al. (2001), it was predicted that faces of persons subsequently rated good/liked would be selected more often than faces of persons subsequently rated evil/disliked. That is, given the choice of a good/liked famous person and an unfamiliar person, participants would tend to select the famous face, but given the choice of an evil/disliked famous person and an unfamiliar person, participants would tend to select the unfamiliar face. In particular, if evil/disliked faces were selected below chance, this would demonstrate that recognition had occurred and that recognition was not accompanied by awareness precisely because this would be contrary to the task instruction.

It should be noted that these experiments do not investigate the mere exposure effect, which would predict the above-chance selection of famous faces due to their familiarity, but rather the opposite in the case of evil faces. It was predicted that faces of evil persons would be selected below chance due to their negative valence.

\section{EXPERIMENT 1}

\section{Method}

Participants. Participants were 34 students, staff, and visitors at Goldsmiths College, London. Every participant's individual performance was at chance in selecting famous as opposed to unfamiliar faces (binomial distribution, one-tailed, $\alpha=.05$ ). Data were excluded from 7 participants who failed to identify a minimum of 8 faces in total, and a minimum of 2 rated good and 2 rated evil, in the postexperimental rating task. The remaining 27 participants were 18 females and 9 males, aged between 20 and 51 years $(M=$ $27.2, S D=7.5$ ). All of the participants had been residents in the United Kingdom for at least 10 years, which should maximize the likelihood of knowledge of the famous faces.

Stimuli. Photographs of famous and unfamiliar faces of a uniform quality were digitized to produce images of 16 grays, $150 \times$ 200 pixels in size. The faces displayed a frontal pose with a nearneutral expression and the direction of eye gaze pointing directly to the camera. Five evil famous persons and five good persons (listed in the Appendix) were each paired with an unknown face of the same sex, race, and approximate age, and with a similar pose and facial expression. Distinctiveness was rated by 10 participants on a 7 -point scale $(1=$ very typical; $7=$ very distinctive $)$. Distinctiveness did not differ between the evil faces and their paired unfamiliar faces $[t(8)=1.34$, n.s.], or between the good faces and their paired unfamiliar faces $[t(8)=0.82$, n.s. $]$. Facial emotional expression was rated by 11 participants on a 7 -point scale $(-3=$ very negative $;+3=$ very positive). Expression did not differ between the evil faces and their paired unfamiliar faces $[t(8)=0.68$, n.s. $]$ or between the good faces and their paired unfamiliar faces $[t(8)=0.62$, n.s.]. The mask was a rectangle of jumbled face parts, all taken from unfamiliar faces, of the same size as the stimuli.

Apparatus. A personal computer running MEL2 software was used to display the faces at a $640 \times 480$ screen resolution. Accuracy of response was measured and recorded by the computer.

Design. The within-subjects factor was valence of famous face, defined by each participant for each item in a postexperimental rating task, and the dependent variable was accuracy of response. Each face pair was presented four times, with the famous face appearing twice each in LVF and RVF, giving 40 trials in total. The trials were presented in a sequence randomized by the computer for each participant. The exposure duration of $17 \mathrm{msec}$ (defined as target-tomask SOA) was selected from the technologically available options of 17 or $33 \mathrm{msec}$ following pilot studies suggesting conscious perception on up to $10 \%$ of trials at $33 \mathrm{msec}$ but fewer than $1 \%$ of trials at $17 \mathrm{msec}$ with faces presented singly.

Procedure. Another, unrelated, task preceded the task reported here, in which masked faces were presented for $17 \mathrm{msec}$. Participants performed individually in a darkened, air-conditioned room at a constant level of background lighting. The task was described and participants were instructed to guess their responses if they were unable to see the faces. Following 8 practice trials, the 40 experimental trials were presented in a sequence randomized by computer for each participant. The faces were presented simultaneously at a distance of $9 \mathrm{~cm}$ apart with each face subtending a visual angle of approximately $2.6^{\circ} \times 4^{\circ}$. Each trial consisted of the following sequence: a central fixation point, forward masks in LVF and RVF for $100 \mathrm{msec}$, famous and unfamiliar face for $17 \mathrm{msec}$, immediately followed by backward masks in LVF and RVF for $100 \mathrm{msec}$, and finally the question "left or right?" displayed until the participant responded. Each trial was initiated by the response to the preceding trial after an intertrial interval of $1 \mathrm{sec}$. Participants were required to select on which side of the screen the famous face had appeared. They were asked to respond as accurately as possible but were not asked to respond quickly.

After the computer task, participants were asked about their perception during the task. Then they were shown the famous faces used in the experiment and asked to identify each face and provide a rating of valence $(-3=$ very evil; $0=$ neutral $;+3=$ very good $)$. Participants were instructed that they should give their personal opinion, considering their knowledge of each famous person. Finally, participants were debriefed and thanked for their participation.

\section{Results and Discussion}

If a participant was unable to identify a famous face in the postexperimental rating task, the responses for this combination of participant and item were excluded from the analysis. Responses faster than $200 \mathrm{msec}$ from face offset were excluded as probable anticipations. Slow responses were included because participants had not been asked to respond quickly. Faces were classified as evil or good according to the participant's own rating, with faces rated zero being classified as good.

All participants insisted they had been unable to recognize any of the faces during the experimental task. 
Most participants had occasionally perceived face outlines or individual features, either eyes or mouth. The mean proportion of correct responses to famous faces was .469 , obviously not above the chance level of .50, consistent with participants' self-report and confirming the absence of conscious recognition. The prediction of lower accuracy for evil faces was confirmed: A lower proportion of evil faces $(M=.441, S D=.11)$ than of good faces $(M=.508, S D=.11)$ were selected [paired-samples $[t(26)=1.99, p<.03$, one-tailed]. One-sample $t$ tests revealed that evil faces were selected significantly less often than chance $[t(26)=-2.68, p<.01$, one-tailed], and good faces were selected at chance $[t(26)=0.37$, n.s]. (See Figure 1.)

Below-chance selection of evil faces demonstrates that participants had detected unique facial identity and affective valence, and done so without awareness since below-chance selection of the evil faces was contrary to the task instruction.

Participants had been asked to choose between a famous and an unfamiliar face on each trial, where the faces differed slightly on distinctiveness and on facial expression. A possible confound exists if the good faces differed from their paired unfamiliar faces in such a way that the good faces were more likely to be selected, while the evil faces differed from their paired unfamiliar faces in the opposite direction. Paired-samples $t$ tests were performed by applying the preexperimental ratings of expressions and distinctiveness to the faces in the categories of evil and good as defined by each experimental participant. Regarding distinctiveness, the evil faces $(M=$ $5.06, S D=0.29$ ) were more distinctive than their paired unfamiliar faces $[M=4.44, S D=0.16 ; t(26)=8.50$, $p<.001]$. The good faces $(M=4.82, S D=0.23)$ were also more distinctive than their paired unfamiliar faces $[M=4.20, S D=0.21 ; t(26)=9.27, p<.001]$. The variation in distinctiveness favored both good and evil faces over unfamiliar faces, and so it cannot explain the superior selection of good faces over evil faces. Regarding facial expression, the evil faces $(M=-.42, S D=.28)$

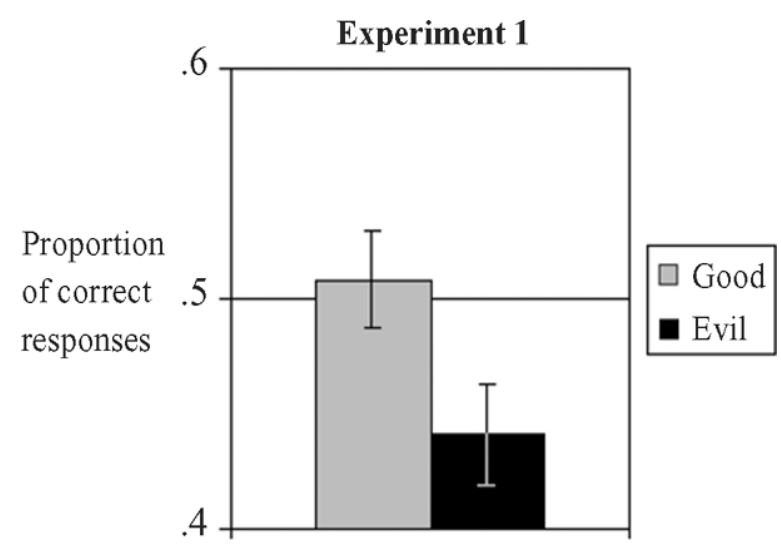

Figure 1. Mean accuracy of responses to good and evil faces in Experiment 1, analysis by participants. Bars represent standard errors. had more positive expressions than the paired unfamiliar faces $[M=-.60, S D=.07 ; t(26)=3.81, p<.001]$. The good faces $(M=.20, S D=.47)$ also had more positive expression than the paired unfamiliar faces $[M=-.36$, $S D=.12 ; t(26)=6.47, p<.001]$. The variation in facial expression favored both good and evil faces over unfamiliar faces, and so it cannot explain the superior selection of good faces over evil faces.

Despite the control used to match good and evil faces on key characteristics, it could be argued that the results were due to variation in some other visual characteristics that differed systematically between faces of "good" and "evil" people. Any such artifact could be eliminated by an experiment in which the manipulation of valence involves a within-items comparison. This strategy was adopted in Experiment 2.

\section{EXPERIMENT 2}

Stimuli in Experiment 2 were the faces of 32 famous persons, liked and disliked in roughly equal proportions by participants $(n=56)$ in a previous unpublished experiment. Each participant in the present experiment rated all of the 32 faces as liked or disliked. For each participant, liked and disliked faces were selected according to the participant's own ratings. For each item, participants who liked and disliked the item were selected according to the same ratings.

The affective priming literature shows that priming is obtained with SOA of up to $300 \mathrm{msec}$ but is unreliable at longer SOA (e.g., de Houwer, Hermans, \& Eelen, 1998; Glaser \& Banaji, 1999; Hermans, de Houwer, \& Eelen, 1994, 2001; Klauer, Rossnagel, \& Musch, 1997; see Fazio, 2001, for a review). These data suggest that the valence of a stimulus is rapidly activated and then either decays or is suppressed quickly. The exact speed of activation and decay or suppression may depend on the stimulus exposure, with a longer duration of neural computation required for very briefly exposed stimuli. It seems likely that a strong effect of valence of facial identity might be found in the present experiment if participants were asked to respond quickly. Therefore, instructions to respond quickly were emphasized in Experiment 2.

\section{Method}

Only the relevant differences from Experiment 1 will be described here.

Participants. Participants were 22 students at Goldsmiths College, London. Data were excluded from 1 participant who lacked familiarity with the famous faces and from 1 participant who selected more famous faces than were expected by chance (binomial distribution, one-tailed, cutoff at $57 \%, \alpha=.05$ ) since for this participant the possibility of some partial awareness cannot be ruled out. The remaining 20 participants were 16 females and 4 males, aged between 18 and $42(M=23.6, S D=5.7)$.

Stimuli. The stimulus set comprised 32 pairs of one famous and one unfamiliar face matched on sex, race, and approximate age, and with a similar pose and facial expression. Names are listed in Table 1.

Design. Stimuli were presented once each in four blocks of 32 trials, giving a total of 128 trials. Face pairs were randomly divided into two sets. Half the participants saw the first set with the famous 
Table 1

Breakdown of Item Data

\begin{tabular}{lrcccc}
\hline \multicolumn{1}{c}{ Face } & $\begin{array}{c}\text { No. } \\
\text { disliked }\end{array}$ & $\begin{array}{c}\text { No. } \\
\text { liked }\end{array}$ & $\begin{array}{c}\text { Proportion } \\
\text { disliked }\end{array}$ & $\begin{array}{c}\text { Accuracy } \\
\text { disliked }\end{array}$ & $\begin{array}{c}\text { Accuracy } \\
\text { liked }\end{array}$ \\
\hline Tony Blair & 15 & 5 & .75 & .47 & .63 \\
Margaret Thatcher & 13 & 6 & .68 & .38 & .33 \\
Michael Barrymore & 10 & 7 & .59 & .41 & .63 \\
William Hague & 10 & 7 & .59 & .41 & .42 \\
Geri Halliwell & 11 & 8 & .58 & .31 & .53 \\
Liam Gallagher & 9 & 7 & .56 & .44 & .50 \\
John Major & 9 & 7 & .56 & .56 & .57 \\
Yasser Arafat & 8 & 7 & .53 & .41 & .60 \\
Naomi Campbell & 10 & 9 & .53 & .50 & .57 \\
Jeremy Beadle & 6 & 6 & .50 & .57 & .43 \\
John Prescott & 7 & 8 & .47 & .48 & .52 \\
Puff Daddy & 7 & 9 & .44 & .39 & .44 \\
Paul Daniels & 6 & 8 & .43 & .52 & .48 \\
Chris Evans & 8 & 11 & .42 & .48 & .55 \\
Jennifer Lopez & 8 & 11 & .42 & .34 & .56 \\
Victoria Beckham & 8 & 12 & .40 & .63 & .55 \\
Prince Charles & 7 & 13 & .35 & .46 & .58 \\
Robbie Williams & 7 & 13 & .35 & .33 & .54 \\
Britney Spears & 6 & 11 & .35 & .48 & .50 \\
Queen Elizabeth & 6 & 13 & .32 & .39 & .55 \\
Anne Widdecombe & 5 & 11 & .31 & .33 & .49 \\
Michael Jackson & 6 & 14 & .30 & .59 & .62 \\
Camilla Parker-Bowles & 4 & 11 & .27 & .38 & .51 \\
Whitney Houston & 5 & 14 & .26 & .58 & .47 \\
Anne Robinson & 5 & 14 & .26 & .58 & .42 \\
Richard Madeley & 4 & 14 & .22 & .57 & .53 \\
Russell Crowe & 3 & 14 & .18 & .40 & .60 \\
Leonardo Dicaprio & 3 & 17 & .15 & .58 & .52 \\
Liz Hurley & 3 & 17 & .15 & .58 & .56 \\
Mick Jagger & 2 & 14 & .13 & .14 & .46 \\
\hline Note-Column & & & & .13 \\
\hline
\end{tabular}

Note - Columns 2 and 3 show the number of participants rating the face as disliked/liked; column 4 shows the proportion of participants rating the face as disliked; columns 5 and 6 show the mean accuracy of responses to the face calculated over participants rating the face as disliked/liked.

face in the LVF in Blocks 1 and 3 and in the RVF in Blocks 2 and 4 , and the second set with the famous face in the RVF in Blocks 1 and 3 and the LVF in Blocks 2 and 4. The other half of the participants had the alternative arrangement. This design ensured equal numbers of famous faces in LVF and RVF in each block and minimized the likelihood that the same face would be presented twice in succession. Within each block, the sequence of presentation was randomized by the computer for each participant. There was one within-items and one within-subjects factor of valence.

Procedure. The postexperimental rating question was changed to use the terms like and dislike rather than good and evil. Participants were asked to respond quickly on each trial, and this instruction was emphasized after the practice trials had been completed.

\section{Results and Discussion}

If a participant was unable to identify uniquely a famous face in the postexperimental rating task, the trials for this combination of participant and item were excluded from the analysis ( $12 \%$ of trials). Responses faster than $200 \mathrm{msec}$ from face offset were excluded as probable anticipations (3.2\% of trials), and responses slower than $1,500 \mathrm{msec}$ were excluded because participants had been asked to respond quickly (1.7\% of trials). Faces were classified as liked or disliked according to the participant's own rating, with faces rated as zero being classified as liked in order to distinguish between disliked persons and the rest. Faces were included in the analysis if they were rated disliked by at least 2 participants, resulting in the inclusion of 30 of the original 32 items. The participants' analysis was calculated over these items. The percentage of participants rating each face as disliked ranged from $13 \%$ to $75 \%$ with a mean of $40 \%$.

All participants insisted they had been unable to recognize any of the faces during the experimental task. Most participants had occasionally received vague impressions of face outlines and a minority had perceived gender on one or two trials, or had seen a pair of glasses. The mean proportion of correct responses to famous faces was .496 , obviously not above the chance level of .50 , consistent with participants' self-report and confirming the absence of conscious recognition.

For each participant, mean accuracy was calculated over the faces rated as liked and separately over the faces rated as disliked. So two values were calculated for each participant: accuracy-liked $(M=.524, S D=.05)$ and accuracy-disliked $_{\mathrm{p}}(M=.432, S D=.09)$. Similarly, for each face, mean accuracy was calculated over all participants rating the face as liked and separately over all participants rating the face as disliked. So two values were calculated for each face: accuracy-liked $(M=.522, S D=$ $.07)$ and accuracy-disliked $(M=.457, S D=.11)$. Where a face was liked and disliked in unequal proportions, different numbers of participants contributed to the calculation of accuracy-liked ${ }_{\mathrm{i}}$ and accuracy-disliked ${ }_{\mathrm{i}}$.

Paired-samples $t$ tests by participants $\left(t_{\mathrm{p}}\right)$ and by items $\left(t_{\mathrm{i}}\right)$ revealed that disliked faces were selected less often than liked faces $\left[t_{\mathrm{p}}(19)=4.80, p<.001\right.$, and $t_{\mathrm{i}}(29)=$ $2.89, p<.005$ (one-tailed)]. One-sample $t$ tests comparing accuracy against the chance level of .50 showed that disliked faces were selected below chance $\left[t_{\mathrm{p}}(19)=\right.$ $-3.40, p<.005$, and $\left.t_{\mathrm{i}}(29)=-2.14, p<.025\right]$. Liked faces were selected above chance $\left[t_{\mathrm{p}}(19)=2.17, p<\right.$ .025 , and $\left.t_{\mathrm{i}}(29)=1.72, p<.05\right]$. Table 1 and Figure 2 show accuracy-liked ${ }_{i}$ and accuracy-disliked ${ }_{i}$ for each item, as well as the number of participants rating the face as liked and disliked.

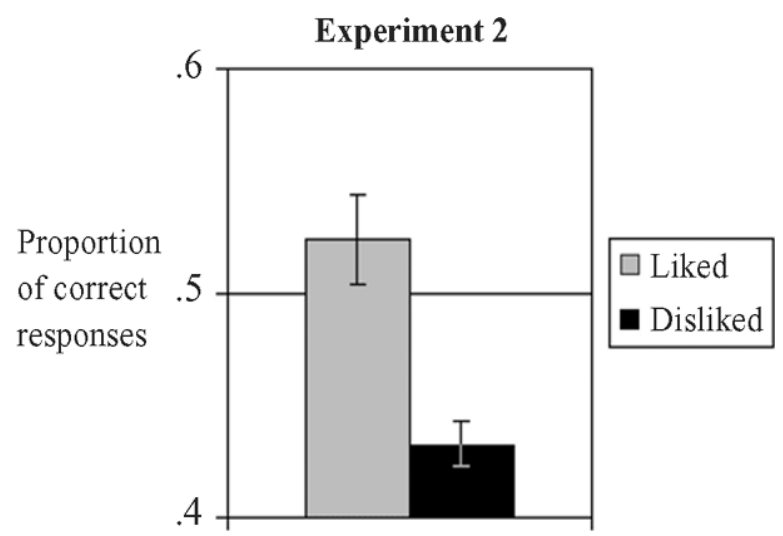

Figure 2. Mean accuracy of responses to liked and disliked faces in Experiment 2, analysis by participants. Bars represent standard errors. 
As in Experiment 1, below-chance selection of disliked faces demonstrates that participants had detected unique facial identity and affective valence, and done so without awareness since below-chance selection of disliked faces was contrary to the task instruction. The within-items analysis rules out confounds based on variations in physical characteristics of the stimulus faces.

\section{GENERAL DISCUSSION}

Experiment 1 demonstrated that, although instructed to select the famous face in a pair, participants were significantly more likely to select the unfamiliar face instead, when the famous face belonged to a person rated evil. Experiment 2 replicated this effect with faces rated disliked and also showed that faces rated liked were selected above chance. The within-items analysis in Experiment 2 rules out possible confounds based on physical characteristics of the faces and confirms that the effects are due to participant attitudes toward the famous persons.

Experiment 2 used persons who were not known for particularly evil or violent deeds and so were not likely to have been regarded as specifically threatening. The effect generalized to persons who were merely disliked, although in a sense the face of a disliked person does threaten to invoke an unpleasant emotional experience.

In terms of the Breen et al. (2000) model, responses to evil/disliked faces were determined more by the affective route than by the semantic route. The negative valence associated with these faces was sometimes sufficiently powerful to override the familiarity signal. Participants may have tended to select the good/liked faces because of either their familiarity or their positive valence. The data presented here do not permit these two possibilities to be distinguished. The study by Greve and Bauer (1990) is suggestive in this respect. Their prosopagnosic participant was presented with pairs of faces in which one had been studied in an earlier phase and the other was new. The participant selected more of the previously studied faces when asked to select the preferred face than when explicitly asked to select the previously studied face. The preference for the previously studied face can be explained in terms of the mere exposure effect, which states that a familiar item tends to be preferred over an unfamiliar item, all other things being equal (Zajonc, 1980; see Zajonc, 2001, for a review). The Greve and Bauer study suggests that preference could be detected more strongly than familiarity per se.

The above-chance selection of liked faces in Experiment 2 can be compared with the performance of prosopagnosic participants given a similar task of deciding which of two simultaneously presented faces is familiar. A number of studies have reported that densely prosopagnosic participants cannot achieve accuracy above the level of chance in this task (e.g., Bobes et al., 2003; De Haan, Bauer, \& Greve, 1992; De Haan, Young, \& Newcombe, 1992; Diamond, Valentine, Mayes, \& Sandel, 1994; Newcombe, Young, \& De Haan, 1989; Sergent \& Signoret,
1992; Sperber \& Spinnler, 2003; Young \& De Haan, 1988). This is somewhat surprising since other measures of covert face recognition demonstrate some preservation of ability to retrieve semantic information, suggesting that the faces must have been recognized, albeit without awareness. Stone and Valentine (2003) presented an analysis suggesting that although each participant shows performance not significantly above chance when considered as a single case study, the participants may be above chance accuracy when analyzed as a group. Although performance is severely impaired, it may have been premature to conclude that densely prosopagnosic participants are entirely unable to detect familiarity in a direct test.

Esteves and Öhman (1993) theorized that early processes in visual perception may respond to particular stimulus features associated with threat. For example, angry expressions may be detected from individual features such as angle of eyebrows. This does not apply to detection of facial identity since recognition of a specific individual requires a holistic, structural perception of the face. That significant effects were found with facial identity indicates that a structural analysis of considerable detail was available from 17-msec masked exposure without resulting in awareness.

In conclusion, the two experiments reported here suggest that facial identity is recognized preconsciously, that the valence associated with a known face is activated automatically, and that unfamiliar faces are selected in preference to the faces of evil/disliked persons.

\section{REFERENCES}

Bobes, M. A., Lopera, F., Garcia, M., Diaz-Comas, L., Galan, L., \& VALdes-Sosa, M. (2003). Covert matching of unfamiliar faces in a case of prosopagnosia: An ERP study. Cortex, 39, 41-56.

Breen, N., Caine, D., \& Coltheart, M. (2000). Models of face recognition and delusional misidentification: A critical review. Cognitive Neuropsychology, 17, 55-71.

BRUCE, V., \& YounG, A. (1986). Understanding face recognition. British Journal of Psychology, 77, 305-327.

Burton, A. M., Bruce, V., \& Johnston, R. A. (1990). Understanding face recognition with an interactive activation model. British Journal of Psychology, 81, 361-380.

De HaAn, E. H. F., BAuer, R. M., \& Greve, K. W. (1992). Behavioural and physiological evidence for covert face recognition in a prosopagnosic patient. Cortex, 28, 77-95.

De Haan, E. H. F., Young, A. W., \& Newcombe, F. (1992). Neuropsychological impairment of face recognition units. Quarterly Journal of Experimental Psychology, 44A, 141-175.

De Houwer, J., Hermans, D., \& Eelen, P. (1998). Affective and identity priming with episodically associated stimuli. Cognition \& Emotion, 12, 145-169.

DiAmond, B. J., VAlentine, T., Mayes, A. R., \& Sandel, M. E. (1994). Evidence of covert recognition in a prosopagnosic patient. Cortex, 30, 377-393.

DiMBERG, U., \& Öhman, A. (1996). Behold the wrath: Psychophysiological responses to facial stimuli. Motivation \& Emotion, 20, 149-182.

Dimberg, U., Thunberg, M., \& Elmehed, K. (2000). Unconscious facial reactions to emotional facial expressions. Psychological Science, 11, 86-89.

ELLIS, H. D., Young, A. W., \& Koenken, G. (1993). Covert face recognition without prosopagnosia. Behavioural Neurology, 6, 27-32.

Esteves, F., \& Öhman, A. (1993). Masking the face: Recognition of emotional facial expressions as a function of the parameters of backward masking. Scandinavian Journal of Psychology, 34, 1-18. 
FAZIO, R. H. (2001). On the automatic activation of associated evaluations: An overview. Cognition \& Emotion, 15, 115-141.

Glaser, J., \& BanaJi, M. R. (1999). When fair is foul and foul is fair: Reverse priming in automatic evaluation. Journal of Personality \& Social Psychology, 77, 669-687.

GREVE, K. W., \& BAUER, R. M. (1990). Implicit learning of new faces in prosopagnosia: An application of the mere-exposure paradigm. Neuropsychologia, 28, 1035-1041.

Hermans, D., DE Houwer, J., \& Eelen, P. (1994). The affective priming effect: Automatic activation of evaluative information in memory. Cognition \& Emotion, 8, 515-533.

Hermans, D., DE Houwer, J., \& Eelen, P. (2001). A time course analysis of the affective priming effect. Cognition \& Emotion, 15, 143-165.

JoHNSEN, B. H., \& HugdaHL, K. (1991). Hemispheric asymmetry in conditioning to facial emotional expressions. Psychophysiology, 28, 154-162.

Johnsen, B. H., \& Hugdahl, K. (1993). Right hemisphere representation of autonomic conditioning to facial emotional expressions. Psychophysiology, 30, 274-278.

Klauer, K. C., Rossnagel, C., \& Musch, J. (1997). List-context effects in evaluative priming. Journal of Experimental Psychology: Learning, Memory, \& Cognition, 23, 246-255.

MoGG, K., \& BRADLEY, B. (1999). Orienting of attention to threatening facial expressions presented under conditions of restricted awareness. Cognition \& Emotion, 13, 713-740.

Morrison, D. J., Bruce, V., \& Burton, A. M. (2000). Covert face recognition in neurologically intact participants. Psychological Research, 63, 83-94.

MURPHY, S. T., \& ZAJONC, R. B. (1993). Affect, cognition, and awareness: Affective priming with optimal and suboptimal stimulus exposures. Journal of Personality \& Social Psychology, 64, 723-739.

Newcombe, F., Young, A. W., \& De HaAn, E. H. F. (1989). Prosopagnosia and object agnosia without covert recognition. Neuropsychologia, 27, 179-191.

NiEDENTHAL, P. M. (1990). Implicit perception of affective information. Journal of Experimental Social Psychology, 26, 505-527.
Öhman, A., Esteves, F., \& Soares, J. J. F. (1995). Preparedness and pre-attentive associative learning: Electrodermal conditioning to masked stimuli. Journal of Psychophysiology, 9, 99-108.

Robinson, M. D. (1998). Running from William James' bear: A review of preattentive mechanisms and their contributions to emotional experience. Cognition \& Emotion, 12, 667-696.

Saban, S., \& HugDaHL, K. (1999). Nonaware classical conditioning to pictorial facial stimuli in a between-groups paradigm. Integrative Physiological \& Behavioral Science, 34, 19-29.

SERGENT, J., \& SignORET, J.-L. (1992). Implicit access to knowledge derived from unrecognized faces in prosopagnosia. Cerebral Cortex, 2, 389-400.

SPERber, S., \& SPINNLER, H. (2003). Covert person recognition: Its fadeout in a case of temporal lobe degeneration. Cortex, 39, 57-67.

Stone, A., \& Valentine, T. (2003). Viewpoint: Perspectives on prosopagnosia and models of face recognition. Cortex, 39, 31-40.

Stone, A., Valentine, T., \& Davis, R. (2001). Face recognition and emotional valence: Processing without awareness by neurologically intact participants does not simulate covert recognition in prosopagnosia. Cognitive, Affective, \& Behavioral Neuroscience, 1, 183-191.

Whalen, P. J., Rauch, S. L., Etcoff, N. L., McInerney, S. C., Lee, M. B., \& JENIKE, M. A. (1998). Masked presentations of emotional facial expressions modulate amygdala activity without explicit knowledge. Journal of Neuroscience, 18, 411-418.

Wong, P. S., Shevrin, H., \& WILLIAMs, W. J. (1994). Conscious and nonconscious processes: An ERP index of an anticipatory response in a conditioning paradigm using visually masked stimuli. Psychophysiology, 31, 87-101.

Young, A. W. (1998). Face \& mind. Oxford: Oxford University Press. Young, A. W., \& De HaAn, E. H. F. (1988). Boundaries of covert recognition in prosopagnosia. Cognitive Neuropsychology, 5, 317-336.

ZaJonc, R. B. (1980). Feeling and thinking: Preferences need no inferences. American Psychologist, 35, 151-175.

ZaJONC, R. B. (2001). Mere exposure: A gateway to the subliminal. Current Directions in Psychological Science, 10, 224-228.

\section{APPENDIX
Famous Faces in Experiment 1}

\begin{tabular}{ll}
\hline Evil Faces (from participants' ratings) & \multicolumn{1}{c}{ Good Faces } \\
\hline Adolf Hitler & Cliff Richard (singer) \\
Myra Hindley (murderess) & Richard Gere (film actor) \\
Saddam Hussein (Iraqi dictator) & John F. Kennedy (U.S. president) \\
Mike Tyson (rapist) & Chris Evans (U.K. TV presenter) \\
Margaret Thatcher (U.K. prime minister) & Mick Jagger (singer) \\
\hline
\end{tabular}

(Manuscript received April 16, 2003;)

revision accepted for publication June 30,2003.) 